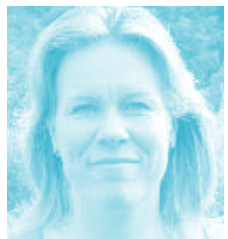

Eva Biringer, leiar i Nettverk for forsking på behandlingsliner og samhandling og norsk nasjonal seksjon av European Pathway Association (E-P-A), Helse Fonna HF
Olav G. Klausen,
adm.dir., Helse Fonna HF

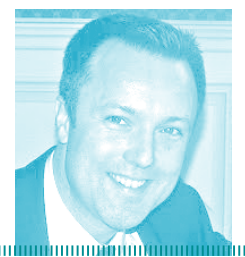

Birger Norderud Lærum, overlækjar, Haukeland universitetssykehus

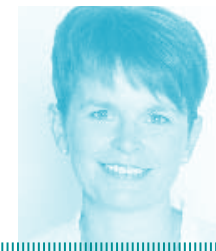

Miriam Hartveit, sjukepleiar, PhD-stipendiat, Helse Fonna HF og Institutt for samfunnsmedisinske fag, UiB
Kris Vanhaecht, sju-

kepleiar og postdok-

tor-stipendiat, Det

katolske universitet,

Leuven, Belgia

\title{
Betre kvalitet med behandlingsliner
}

\author{
Standardiserte behandlingsliner er et verkty som kan betre pasienttryggleiken og ressursutnyttinga.
}

0 tandardiserte behandlingsliner (pasientforløp/care pathways) er i aukande grad brukte internasjonalt som verkty for kvalitetsbetring i helsetenesta (1). Slike standardiserte behandlingsliner betrar ei rekke prosess- og utkommemål. Tilnærminga er oftast brukt innan sjukehus på homogene pasientgrupper med einsarta forløp. Men behandlingslinene har også stort potensiale for bruk på grupper med meir komplekse behov og i tverrsektoriell samhandling.

\section{Standardisert behandlingsline}

Der er mange ulike definisjonar av standardiserte

\section{Hovedbudskap}

Standardisering av behandlingsliner/pasientforløp er nyttig verkty til kvalitetsforbetring i helsetenesta. European Pathway Association (E-P-A) er ein internasjonal organisasjon som spreier kunnskap om behandlingsliner («care pathways»). Slike behandlingsliner kan også vise seg nyttige i tverrsektoriell samhandling.

\section{Søkeord}

Les mer og finn litteraturhenvisninger på våre nettsider. | Kvalitet | Leiing / Organisring behandlingsliner (2), og terminologien, til dømes pasientforløp, «critical-/clinical pathway», «care track», varierer (2). European Pathway Association (E-P-A, sjå www.e-p-a.org) er ein non-profit organisasjon for nettverk, brukargrupper, akademiske institusjonar, sjukehus, støtteorganisasjonar og tilsette i helsetenestene som ynskjer bidra til utvikling og implementering av standardiserte behandlingsliner. Organisasjonen har sterkt fokus på evidensbaserte tiltak og forsking. E-P-A definerer ei standardisert behandlingsline («care pathway») slik (3, 4): «Ei behandlingsline er ein kompleks intervensjon som har gjensidig taking av avgjerder og organisering av behandlingsprosessen for ei definert gruppe pasientar i ein definert tidsperiode som mål. Karakteristika ved ei standardisert behandlingsline er (2-4):

> ei eksplisitt uttrykt utsegn om måla og nøkkelelementa i behandlinga basert på evidens, beste praksis og pasientane sine karakteristika og forventningar

I tilrettelegging for kommunikasjon mellom teammedlemmene, pasientane og deira pårørande

\ koordinering av behandlingsprosessen ved å koordinere rollene og aktivitetane stegvis (sekvensielt) i det tverrfaglege teamet, med omsyn til pasientane og dei pårørande I dokumentering, monitorering og evaluering av variasjonar og utkommer

> identifisering av naudsynte ressursar

Målet med å standardisere pasientforløpa er altså å betre kvaliteten av pleie og behandling gjennom heile behandlingsforløpet ved å betre risikojusterte pasientutkommer, betre pasienttryggleik og optimalisere ressursutnyttinga. Ein slik definisjon av standardiseringa av behandlingsprosessen som over, er langt meir strikt enn mange andre kvalitetsbetringsintervensjonar.

\section{Effekt}

Mange internasjonale studier gjennomført dei siste tjue åra har vist at standardiserte behandlingsliner har effekt. Mest overtydande evidens er difor at implementeringa av desse betrar pasientutkommer og kostnad-nytte-ratioet (5-8). Men der er også mange studier som har vist at implementeringa av standardiserte behandlingsliner fører til kortare liggetid, lågare insidens av postoperative komplikasjonar og betra dokumentasjon $(6,9)$. Standardiseringa er best eigna på homogene pasientgrupper der alle skal gjennomgå det samme i løpet av sjukehusopphaldet. Difor er denne tilnærminga ofte 


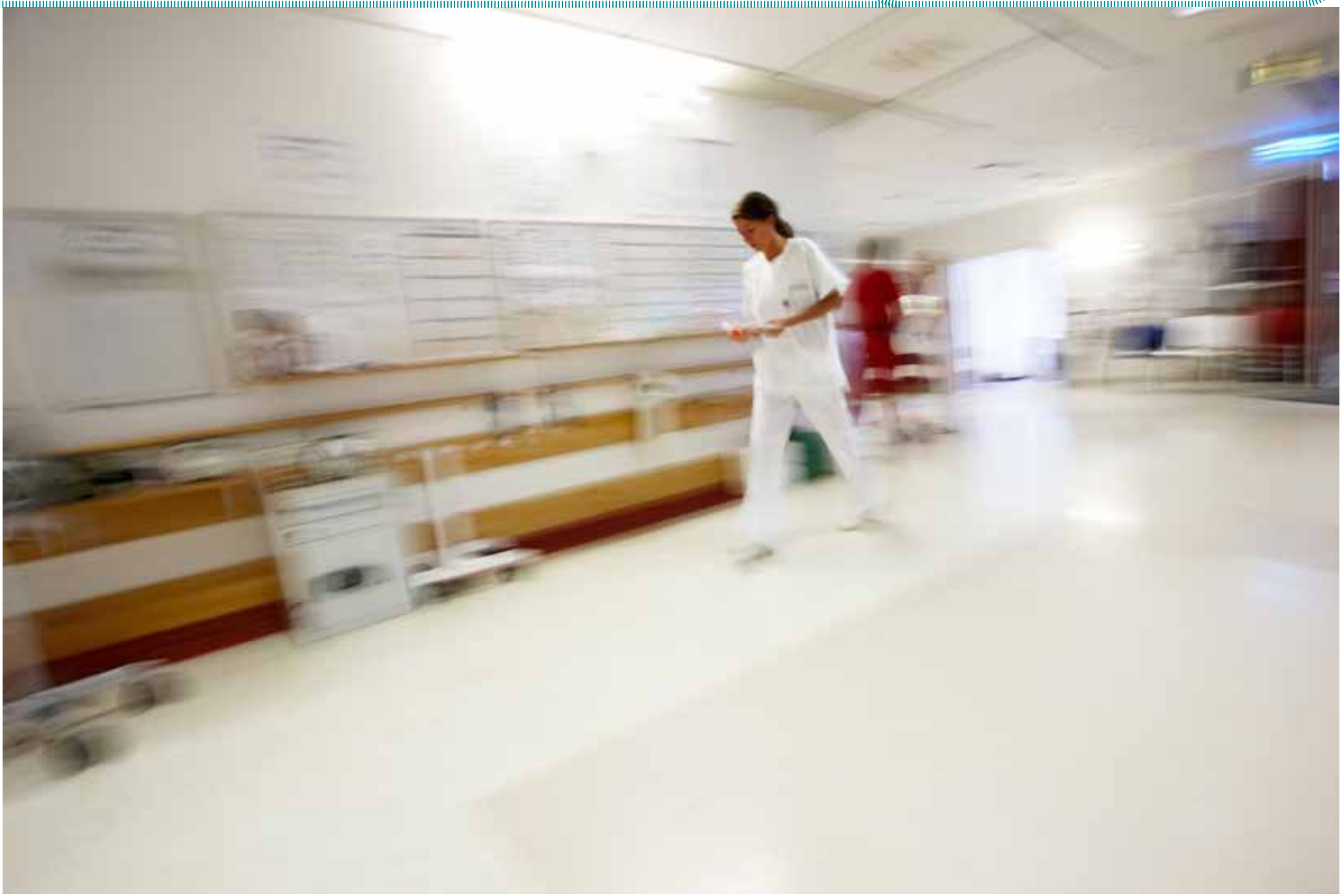

NYTTIG VERKTY: Standardiserte behandlingsliner er oftast brukt innan sjukehus på homogene pasientgrupper med einsarta forløp, men har også stort potensiale for bruk på grupper med meir komplekse behov og i tverrsektoriell samhandling. Arkivfoto: Erik M. Sundt.



FIGUR 1: Utbreiing av «care pathways» i the Belgian Dutch Network (Belgia og Holland). Gitt att med tillating fra European Pathway Association (E-P-A). nytta i kirurgiske fag, særleg i elektiv kirurgi (figur 1). Men tilnærminga er også forsøkt i pasientutval med lågare grad av prediktabilitet i åtferd og behandlingsbehov, der såkalla Hub-, eller Web-modellar for organiseringa av helsetenesta er meir eigna enn ei enkel line(Chain-)tilnærming (10). Dette gjeld til dømes i rehabilitering (11), rus, psykiatri $(12,13)$ og palliativ behandling (14). I slike studier finn ein ofte ei meir fleirsidig tilnærming med element av «case management».

\section{Framgangsmåte}

Planlegginga og implementeringa av behandlingslina for den utvalde pasientgruppa føregår i den enkelte kliniske eininga med utgangspunkt i det kliniske mikroteamet og Plan-Do-CheckAct (PDCA-) sirkelen (Deming's sirkel) (15). Triaden av engasjert sjukepleiar (ansvarleg for det praktiske, til dømes møteinnkallingar og registrering av data), engasjert klinikar (til dømes overlækjar), og einingsleiar vil ofte vere eit godt utgangspunkt. Gruppa som arbeider med behandlingslina skal vere tverrfagleg og alle grupper som har med pasienten å gjere skal 




FIGUR 2: European Pathway Association (E-P-A) si sju-fase tilnærming til planlegging og implementering av ei standardisert behandlingsline. Gitt att med tillating fra European pathway Association (E-P-A).

vere representerte, også til dømes laboratorietenestene. Ein pasientrepresentant bør vere med for å sikre brukarperspektivet. Det er vanleg at ein kompetent kvalitetsrådgjevar (fasilitator) gir råd i planlegginga og implementeringa, som ofte strekker seg over seks til ni månader. Kvalitetsrådgjevar har oversikt over aktuelle verkty som kan nyttast i prosessen (til dømes tre-tavleteknikk (16), Gantt-diagram, og årsak-verknad diagram). E-P-A har utvikla ein sjufasemodell for planlegging, implementering, evaluering og kontinuerlig oppfølging av ei standardisert lellkontroll (18-21), og/eller at nøkkelelementa i behandlingslinene varierer og ikkje er i tråd med ein overordna definisjon av kva ingredienser ei standardisert behandlingsline skal ha $(2,6)$. Fagfeltet treng meir evidens når det gjeld spørsmåla:

, kva verkar standardiserte behandlingsliner på

(kva pasientgrupper, kva prosess- og utkommemål)?

\ korleis verkar standardiserte behandlingsliner (verksame ingrediensar=?)?

> effekten av tverrsektorielle behandlingsliner

\section{«Mange internasjonale studier gjennomført dei siste tjue åra har vist at standardiserte behandlingsliner har effekt. ॥}

behandlingsline (figur 2). Denne bygger på prinsippet om kvalitetsbetring som ein kontinuerleg prosess, og bør saman med «Leuven Clinical Pathway Compass» (17) vere til hjelp for tilsette i norsk helseteneste som ynskjer lage ei behandlingsline i si eining.

\section{Forskingsbehovet}

Der er i dag behov for meir evaluering av standardiserte behandlingsliner. Mange effektstudier er allereie utført (6), men mange av desse er hemma av låg statistisk styrke på grunn av få deltakarar (18), få indikatorar på prosess- og utkommer (dårleg validitet) $(18,19)$, kort oppfølgingstid (18-21), forskingsdesign utan paral- (særlig relevant i samband med Samhandlingsreformen)?

Nyleg vart det oppretta ein eigen norsk nasjonal seksjon av E-P-A, som ønsker nye norske helsearbeidarar velkomne som medlemmer. Seksjonen heldt eit vellukka tredagars kurs i planlegging og implementering av standardiserte behandlingsliner på Solstrand Fjord Hotel i Os ved Bergen i september 2011. I framtida ønsker E-P-A å inspirere til etablering av gode evidensbaserte standardiserte behandlingsliner i Noreg og til evalueringa av desse. IIII

Fagartikler kan sendes til torhild.apall@sykepleien.no

\section{LITTERATUR}

Vanhaecht K, Bollmann M, Bower K, Gallagher C, Gardini A, Guezo J, et al. Prevalence and use of clinical pathways in 23 countries - an international survey by the European Pathway Association. Jintegr Care Pathways 2006(10):28-34.

2. DeBleserL,DepreitereR, De WaeleK, VanhaechtK, Vlayen J,Sermeus W. Defining pathways. J Nursing Management 2006;14(7):553-63.

3. VanhaechtK, Panella M. Is therestill need for confusion about pathways? International Journal of Care Pathways 2010:14(1): :-3.

4. VanhaechtK, Sermeus W, DeWitteK. General Introduction. In: VanhaechtK SW, De Witte K, editor. The impact of clinical pathways on the organisation of care processes. Leuven: ACCO, 2007: 3-18.

5. Campbell H, Hotchkiss R, Bradshaw N, Porteous M. Integrated care pathways. BMJ 1998: 316: 133-37.

6. Rotter T,Kinsman L, James E, Machotta A, Gothe H, Willis J, et al. Clinical pathways: effects on professional practice, patient outcomes, length of stay and hospital costs (Review). The Cochrane Library. 2010(3).

7. Van HerckP, Vanhaecht K, Sermeus W. Effects of clinical pathways: do they work? Jntegr Care Pathways 2004; 8(3): 95-104.

8. Panella M, Marchisio S, Demarchi M, Manzoli L,Di Stanislao F. Reduced in-hospital mortality for heart failure with clinical pathways: the results of a cluster randomized controlled trial. Qual Saf Health Care 2009; 18: 369-73.

9. Bandolier. Oncare pathways. Bandolier Forum. 2003(July):-1-12.

10. Vanhaecht K, Panella M, VanZelm R, WS. What about care pathways? In: Ellershaw J, editor. Care of the dying. 2nded. Oxford: Oxford University Press, 2010:1-14

11. Falconer JARE, Sutin JA, Strasser DC, Chang RW. The critical pathmethod in strok rehabilitation: lessons from an experiment in cost containment and outcome rehabilitation: lessons from an experiment in costcor
improvement. QRB Qual Rev Bull 1993; 19(1): 8-16.

12. Baver M.McBride L., Williford W. GlickH, Kinosian B, Altshuler L,et al. Collaborative Care for Bipolar Disorder: Part II. Impact on Clinical Outcome, Function, and Costs. Carefor

13. Biringer E, Hartveit M. A future for pathways in mental healthcare in Norway-a discussion paper based on El-Ghorr et al. (2010). International Journal of Care Pathways 2010;accepted.

14. Bookbinder M, Blank AEAE, Wollner D, Lesage P, McHugh, Mea. Improving endof-life care: Development and pilot-test of a clinical pathway. J Pain Symptom Manag 2005; 29(6):529-43.

15. Deming W. Quality Predictivity and Competitive Positions. Cambridge, MS: MIT Press, 1982.

16. Vanhaecht K, Van Zelm R, Van Gerven E, Sermeus W, Bower K, Panella M, et al. The 3-blackboard method as consensus-development exercise for building care pathways. Int J Care Pathways 2010; 15(3): 49-52.

17. Vanhaecht K, Sermeus W. The Leuven Clinical Pathway Compass. Journal of Integrated Care Pathways 2003:7 (1):2-7.

18. Cooney R, Bryant P, Haluck R, Rodgers M, Lowery M. The Impact of a Clinical Pathway for Gastric Bypass Surgery on Resource Utilization. I Surg Res 2001; 98(2): 97-101.

19. Huerta S, Heber D, Sawicki M, LIUC, Arthur D, ALEXANDER P, et al. Reduced length of stay by implementation of a clinical pathway for bariatric surgery in an academic health carecenter Am Surgeon 2001:67(12):1228-35.

20. Rouse A, Tripp B, Shipley S, Pories W, Cunningham P, MacDonald K. Meeting the Challenge of Managed Care Through Clinical Pathways for Bariatric Surgery Obes Surg. 1998;8(5):530-4

21. Yeats M, Wedergren S, Fox N, Thompson J. The Use and Modification of Clinical Pathways to Achieve Specific Outcomes in Bariatric Surgery Am Surgeon. 2005;71(2):152-4(3). 